\title{
Effect of Simultaneous Steam Explosion and Alkaline Depolymerization on Corncob Lignin and Cellulose Structure
}

\author{
X. Ouyang, ,a,\# L. Chen, ${ }^{\text {a, }}$ S. Zhang, ${ }^{\mathrm{b}}$ Q. Yuan, ${ }^{\mathrm{a}}$ \\ W. Wang, a,c," and R. J. Linhardt ${ }^{\mathrm{d}, e, f}$ \\ ${ }^{a}$ College of Life Science and Technology, \\ Beijing University of Chemical Technology, Beijing, 100029, China \\ ${ }^{b}$ Department of Biological Systems Engineering, \\ Washington State University, Pullman, WA 99164-6120, USA \\ 'State Key Laboratory of Pulp and Paper Engineering, \\ South China University of Technology, Guangzhou, China, 510640 \\ ${ }^{\mathrm{d} D e p a r t m e n t s ~ o f ~ C h e m i s t r y ~ a n d ~ C h e m i c a l ~ B i o l o g y, ~}$ \\ ${ }^{e}$ Chemical and Biological Engineering, \\ ${ }^{\mathrm{f} C e n t e r ~ f o r ~ B i o t e c h n o l o g y ~ a n d ~ I n t e r d i s c i p l i n a r y ~ S t u d i e s, ~}$ \\ Rensselaer Polytechnic Institute, 110 8th Street, Troy, NY 12180, USA
}

doi: 10.15255/CABEQ.2017.1251

Original scientific paper

Received: November 20, 2017

Accepted: May 26, 2018

Simultaneous steam explosion and alkaline depolymerization was studied to develop an economic and green process for alkaline pretreatment of lignocellulose. Steam explosion facilitated alkaline delignification and decreased the amount of alkali used during pretreatment. Different amounts of lignin and hemicellulose were removed within 5 min by using different sodium hydroxide concentrations and steam explosion severity. The main component of lignin collected using our simultaneous process was acid-insoluble lignin, reaching a purity of $84 \%$. Structural analysis indicated that steam explosion and sodium hydroxide had a synergistic effect on the removal of lignin and hemicellulose from corncob. The effect to four simultaneous pretreatment process of delignification transformed cellulose I to cellulose II, enhancing the enzymatic conversion of cellulose to glucose from $22 \%$ to $96 \%$. The process of simultaneous steam explosion and alkaline depolymerization shows a potential for application in the lignocellulose biorefinery.

Keywords:

lignin, steam explosion, alkaline depolymerization, cellulose, enzymatic hydrolysis

\section{Introduction}

Lignocellulose requires pretreatment before its biological conversion due to its inherent stability and recalcitrance. Over the past several decades, many lignocellulose pretreatment methods have been developed, including physical, chemical, and biological methods, as well as their combinations $s^{1,2}$. The objective of these pretreatment methods is to modify or fractionate lignin and/or hemicellulose, and disrupt the structure of cellulose to increase its enzymatic conversion to glucose ${ }^{3,4}$. From the standpoint of industrial applications, green processes and economic feasibility are important in critically evaluating pretreatment methods ${ }^{5}$. Consequently, it is essential to develop clean and low cost pretreatment methods for conversion of lignocellulose to its components at industrial scale for use in the biorefinery.

\#These authors contribute to the work equally.

*Corresponding author: E-mail address: wangwy@mail.buct.edu.cn, Tel: 010-64421335
Alkaline reagents, including sodium hydroxide, potassium hydroxide, calcium hydroxide, and ammonium hydroxide, have been used extensively and improve the enzymatic digestion of the resultant cellulose, thus greatly improving sugar recovery ${ }^{6,7,8}$. The influence of alkaline pretreatment on enzymatic hydrolysis can be attributed to effective removal of lignin and to the swelling of cellulose structure ${ }^{9,10,11}$. When sugarcane bagasse was treated at 80 ${ }^{\circ} \mathrm{C}$ for $3 \mathrm{~h}$ with $0.25 \mathrm{M}$ sodium hydroxide at a ratio of solid to liquid as $1 \mathrm{~g}$ to $20 \mathrm{~mL}, 78 \%$ of lignin was removed ${ }^{6}$. Measurement of cellulose swelling indicated that the alteration of the crystalline hydrogen bond network improved the digestibility of cellulose $^{12}$. The crystal index (CrI) of cellulose from Populus decreased by 5 7\%, 7 9\% and 5 9\% in sodium hydroxide, lime, and ammonia pretreatments, compared with untreated samples. These changes in CrI values were attributed to slight disruption of the cellulose crystalline structure ${ }^{10}$. After alkaline treatment, lignin can be collected from the alkaline solution and used as fuel or in the genera- 
tion of value-added products to decrease the cost of lignocellulose utilization ${ }^{13,14}$. Alkaline pretreatment provides a promising process for the lignocellulose industrial utilization. However, alkaline pretreatment usually requires the prolonged treatment of lignocellulose with a large volume of alkaline solution at high temperature. The resulting waste salts and the high-energy consumption constitute a major challenge for environmental protection and the economics of the pretreatment process.

Steam-explosion pretreatment of lignocelluloses is considered to be an efficient method for the removal of hemicellulose and for the disruption of cellulose crystallinity ${ }^{2,5}$. Steam-explosion has been applied for the pretreatment of various lignocelluloses, including wheat straw ${ }^{15}$, sunflower stalks ${ }^{16}, P i$ nus patula ${ }^{17}$, rice straw ${ }^{18}$, switchgrass and sugarcane bagasse $^{19}$, corn stover ${ }^{20}$, and Eucalyptus globulus ${ }^{21}$. We recently described a clean and effective pilot-scale process for the production of xylitol from hemicellulose using an acid-catalyzed steam explosion process $^{22,23}$. Compared with the traditional boiling processes, this acid-catalyzed steam explosion process increased the temperature from $120{ }^{\circ} \mathrm{C}$ to $160 \sim 180{ }^{\circ} \mathrm{C}$, and reduced the acid from $105-300$ $\mathrm{mg} / 100 \mathrm{~g}$ dry mass $(1.5 \sim 2 \%$, liquid-to-solid ratios $7 \sim 15: 1)$ to $9 \mathrm{mg} / 100 \mathrm{~g}$ dry mass $(0.32 \%$, liquid-to-solid ratios $1.5: 1$ ), and time from $120 \mathrm{~min}$ to $5 \sim 10 \mathrm{~min}^{22,23}$. The reason for the reduction in the amount of acid used and the reduced process time was ascribed to the higher temperature and the force of steam explosion. These factors promote the degradation of hemicellulose to xylose improving our xylitol process. This process also substantially reduces waste salts and decreases energy consumption $^{24}$. Subsequently, a high yield of high purity lignin was obtained from corncob by the combination of steam explosion followed by hot ethanol treatment, and this lignin represents a value-added product and improved the enzymatic hydrolysis of cellulose $\mathrm{e}^{25,26}$. However, this process requires steam explosion to be followed by hot ethanol treatment for lignin isolation. On the basis of previous research, we report the development of a process, relying on the simultaneous steam explosion and alkaline depolymerization, carried out on corncob. Our newly developed single treatment process aims at removing lignin and hemicellulose from lignocellulose and affording cellulose with disrupted crystallinity. This new process also reduces the amount of resulting waste salts and reduces energy consumption.

Corn is one of the main crops in China, and there are about 20 million tons of corncobs generated annually from corn ${ }^{27}$. In addition to being a source of raw material for the production of xylitol, almost $50 \%$ of corncobs are burned or simply rep- resent agricultural waste, representing a major environmental challenge. In the present paper, corncobs and sodium hydroxide were used to develop the simultaneous steam explosion and alkaline depolymerization process. The chemical composition of isolated lignin and the enzymatic hydrolysis of resulting cellulose were investigated to evaluate the effect of this pretreatment. The structural variation of the resulting lignin and cellulose were also analyzed to explore the chemical and physical mechanisms of pretreatment to provide guidance for the further development of pretreatment processes.

\section{Materials and methods}

\section{Lignocellulosic biomass}

Untreated corncob (UC) was collected from Shandong Province and chipped to a size of $2 \mathrm{~cm}$, and stored at room temperature. UC was dried in a cross-flow oven at $50{ }^{\circ} \mathrm{C}$ overnight before all experiments. The chemical composition of UC was 38.4 $\%$ glucose, $28.4 \%$ xylose, $0.9 \%$ arabinose, $17.9 \%$ acid insoluble lignin (AIL), $5.3 \%$ acid soluble lig$\operatorname{nin}(\mathrm{ASL})$, and $2.5 \%$ ash.

\section{Simultaneous steam explosion and alkaline depolymerization}

Prior to steam explosion, $100 \mathrm{~g}$ of UC was immersed in $3 \%, 6 \%, 9 \%$ sodium hydroxide solution at the solid/liquid ratio of 1:6 for 2 hours. And then, the corncob was drained to obtain a solid with about $60 \%$ absorbed water content. Simultaneous steam explosion and alkaline depolymerization (SSA) was carried out in the steam-explosion equipment according to Zhang ${ }^{22}$. The drained corncob was put in the steam-explosion equipment and heated to 180 ${ }^{\circ} \mathrm{C}, 190{ }^{\circ} \mathrm{C}, 200{ }^{\circ} \mathrm{C}$ (corresponding to $1.0 \mathrm{MPa}, 1.3$ $\mathrm{MPa}, 1.6 \mathrm{MPa}$, respectively). The steam pressure was held for $5 \mathrm{~min}$, and the pressure was then reduced abruptly to standard atmospheric pressure. The severity factor of steam explosion can be calculated by an empirical equation ${ }^{28}$

Severity factor $=\log _{10} R o=\log _{10}\left[t \cdot \exp \left(\frac{(T-100)}{14.75}\right)\right]$

where $T$ is temperature of steam explosion $\left({ }^{\circ} \mathrm{C}\right)$, and $t$ is the retention time ( $\mathrm{min})$. The steam explosion experiments were carried out as follows. The $t$ was 5 min and values of $T$, including $180{ }^{\circ} \mathrm{C}, 190{ }^{\circ} \mathrm{C}$, $200{ }^{\circ} \mathrm{C}$, were used corresponding to severity factors of $3.05,3.45$ and 3.64, respectively. The three $\mathrm{NaOH}$ concentrations were combined with three severity factors, representing a total of 9 different pretreatment conditions. 
After steam explosion, the treated residue was collected and subjected to filtration. The filter cake (delignified corncob, DC) was washed with the same concentration of sodium hydroxide (solid:liquid = 1:2) and then washed with the water (solid:liquid $=1: 2)$. The solid residues were named $\mathrm{DC}_{3-3.05}$, $\mathrm{DC}_{6-3.05}, \mathrm{DC}_{9-3.05}, \mathrm{DC}_{3-3.45}, \mathrm{DC}_{6-3.45}, \mathrm{DC}_{9-3.45}, \mathrm{DC}_{3-3.64}$, $\mathrm{DC}_{6-3.64}^{6-3.05}, \mathrm{DC}_{9-3.64}^{9-3.05}$ (the first subscript identifying the wt $\%$ sodium hydroxide, and the second subscript identifying the severity factor). The filtrate was acidified to final $\mathrm{pH}$ value of 2 by adding $6 \mathrm{M} \mathrm{HCl}$ to obtain lignin precipitate (lignin from simultaneous steam-explosion and alkaline-depolymerization, L-SSA, using the same subscript designations). All L-SSA samples were separated by certification and

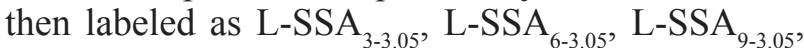
L-SSA $_{3-3.45}, \quad$ L-SSA $_{6-3.45}$, L-SSA ${ }_{9-3.35}, \quad$ L-SSA ${ }_{3-3.364}$, L-SSA $_{6-3.64}$, L-SSA ${ }_{9-3.64}$. L-SSA and DC samples were dried at $50{ }^{\circ} \mathrm{C}$ overnight.

\section{Chemical composition analysis of DC and L-SSA samples}

The chemical compositions of all samples were analyzed by the National Renewable Energy Laboratory (NREL) method ${ }^{29}$. Dried sample $(300 \mathrm{mg})$ was hydrolyzed in a thick-wall flask using $3 \mathrm{~mL}$ of sulfuric acid $(72 \%)$ for $30 \mathrm{~min}$ in a water bath with intermittent shaking every $5 \mathrm{~min}$. After adding 84 $\mathrm{mL}$ water to dilute the $72 \% \mathrm{H}_{2} \mathrm{SO}_{4}$ to $4 \%$, the sample was hydrolyzed at $121{ }^{\circ} \mathrm{C}$ for $60 \mathrm{~min}$ in an autoclave. The hydrolyzed liquid was separated by air pump filtration. The filter cake was dried at $105^{\circ} \mathrm{C}$ for $5 \mathrm{~h}$ and weighed. A portion of the filter cake was placed in a muffle furnace (Zhonghuan, Tianjin, China) at $575{ }^{\circ} \mathrm{C}$ to determine the ash content. The hydrolyzate was analyzed by UV spectrophotometer (Shimadzu UV2450, Japan) to determine acid soluble lignin (ASL). Carbohydrate in the hydrolyzate was measured by high performance liquid chromatography (Hitachi, Tokyo, Japan) equipped with refractive index detector and a Sugar-pak 1 column (Waters, Milford, USA). All the samples were analyzed in triplicate.

\section{Fourier transform infrared spectroscopy (FTIR)}

The FTIR spectra of L-SSA samples were recorded in a Nicolet 6700 spectrophotometer in the scan range from $400 \mathrm{~cm}^{-1}$ to $4000 \mathrm{~cm}^{-1}$ with a resolution of $4 \mathrm{~cm}^{-1}$ to compare the molecular structures of samples. A 200-mg KBr disc containing $1 \mathrm{mg}$ sample was used in FTIR measurements.

\section{Wide angle X-ray scattering (WAXS)}

WAXS was carried out in a Rigaku D/Max $2500 \mathrm{VB} 2+/ \mathrm{PC}$ to measure the crystal index $(\mathrm{CrI})$ of DC, with $5^{\circ} \mathrm{min}^{-1}$ scan speed and $5 \sim 50^{\circ}$ scan scope. Copper radiation $(k=0.154185 \mathrm{~nm})$ was generated at a voltage of $40 \mathrm{kV}$. The crystal index was calculated by the following equation ${ }^{30}$ :

$$
\mathrm{CrI}=\frac{I_{\text {total }}-I_{a m}}{I_{\text {total }}} \cdot 100
$$

where $I_{\text {total }}$ is the scattered intensity at $2 \theta=22.1^{\circ}$, and $I_{a m}$ is the scattered intensity at $2 \theta=16.0^{\circ}$.

\section{Two-dimensional (2D) heteronuclear single-quantum correlation (HSQC) nuclear magnetic resonance (NMR) spectroscopy of L-SSA}

The structural characteristics of the L-SSA samples were determined by a Bruker AV 600 spectrometer at $300 \mathrm{~K}$. About $50 \mathrm{mg}$ lignin was dissolved in $0.5 \mathrm{~mL} \mathrm{~d}_{6}$-DMSO. The spectral widths were $8389 \mathrm{~Hz}$ and $25655 \mathrm{~Hz}$ for ${ }^{1} \mathrm{H}$ and ${ }^{13} \mathrm{C}$, respectively. The number of collected complex points was 2048 for ${ }^{1} \mathrm{H}$ dimension with a recycle delay of $1.5 \mathrm{~s}$. The number of transients was 64 and 256 time increments were recorded in ${ }^{13} \mathrm{C}$ dimension. Data were analyzed by Bruker Topspin software. The DMSO peak $\left(\delta_{\mathrm{C}} / \delta_{\mathrm{H}}=39.5 / 2.49\right)$ was used as an internal standard of chemical shift.

\section{Gel permeation chromatography (GPC)}

The molecular weight of L-SSA was carried out in the Waters GPC system (Milford, Massachusetts, USA) equipped with a UV detector. The column was TSK G3000PWxl (TOSOH, Japan) and different molecular weight $(210,4300,6800,10000$, $17000,32000,150000)$ polystyrene sulfonic acid salts (Sigma-Aldrich) were employed as standards. L-SSA samples were dissolved in $1 \%$ sodium hydroxide solution and diluted to about $2 \mathrm{mg} \mathrm{mL}^{-1}$ with ultrapure water. GPC was performed at room temperature, elution relied on $0.1 \mathrm{M}$ sodium nitrate

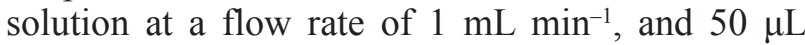
sample was injected into the GPC system.

\section{Enzymatic hydrolysis of DC}

DC samples were hydrolyzed in $50 \mathrm{mM}$ citrate buffer $(\mathrm{pH}=4.8)$ at $50{ }^{\circ} \mathrm{C}$ in an air incubator at 150 $\mathrm{rpm}$. The DC substrate load was $5 \%$, corresponding to $5 \mathrm{~g}$ DC substrate mixed with $100 \mathrm{~mL}$ citrate buffer. Cellulase (Novozyme Cellic CTec2) activity was $206 \mathrm{FPU} \mathrm{mL}^{-1}$ and the enzyme loading was 18 FPU $\mathrm{g}^{-1}$ cellulose. The results of enzymatic hydrolysis were analyzed by HPLC as described in section Chemical composition analysis of DC and L-SSA samples. 


\section{Results and discussion}

\section{Chemical composition analysis of samples after the simultaneous steam explosion and alkaline depolymerization}

Simultaneous steam explosion and alkaline depolymerization was carried out under 9 different conditions. The chemical compositions of lignin from simultaneous steam explosion and alkaline depolymerization (L-SSA) are shown in Table 1. With increasing steam explosion severity and sodium hydroxide impregnation concentration, the xylose content significantly rose from $7 \%$ to $14 \%$, while arabinose and glucose content only increased slightly. Xylose, arabinose, and a portion of the glucose are the main components of hemicellulose, which usually acts as an adhesive in lignocellulose through ether linkages, hydrogen bonding, and Van der Waals forces ${ }^{31}$. The high severity of steam explosion can break chemical bonds between hemicellulose and lignin or hemicellulose and cellulose, resulting in increasing hemicellulose-derived sugar content in L-SSA. Acid insoluble lignin (AIL) is the main component of L-SSA. However, AIL in all L-SSA samples decreases from $84 \%$ to $68 \%$ with the use of higher sodium hydroxide concentrations and higher severity factors. This result is mainly attributable to the base-catalyzed lignin depolymerization $^{32}$. Hydroxyl groups show strong electronegativity and, thus, play a major role in the cleavage of the $\beta-O-4$ linkages in the phenolic units ${ }^{33}$. The chemical composition of L-SSA indicated that more carbohydrate existed in the L-SSA with the increased sodium hydroxide concentrations and in the case of increased steam explosion severity, which resulted for two reasons, more hemicellulose was depolymerized into monosaccharides, and more lignin was deploymerized into soluble lower-weight chemicals by harsh conditions ${ }^{32}$. In conclusion, lig- nin is the main part of chemical composition in L-SSA, and xylose content will increase with the improvement of sodium hydroxide concentration and steam explosion severity.

Table 2 shows the chemical compositions of DC after the SSA pretreatment. The enrichment of glucose in DC samples suggests that the corncob was well delignified under these different conditions. The xylose content shows an interesting variation under different experimental conditions. There is an obvious decrease in xylose content in DC at the highest severity factor of steam explosion, demonstrating that steam pressure has a much greater influence than sodium hydroxide concentration on the removal of hemicellulose from corncob. Hemicellulose is usually difficult to remove completely because of its chemical linkage with lignin or cellulose in the plant cell wall ${ }^{34}$. Steam explosion can provide high temperature and high pressure to enhance the removal of hemicellulose under basic conditions. In addition, the plant cell wall is destroyed when the high pressure is returned to standard pressure within a short time, resulting in the large-scale extraction of hemicellulose under the highest severity factor (3.64). The different effects of steam explosion and sodium hydroxide on lignin and hemicellulose removal can also be indicated by the percentage of removed lignin and hemicellulose (Table S1). The 5-minute steam explosion process facilitated by sodium hydroxide removes most $(>80$ $\%$ ) of the lignin from corncob under the various experimental conditions. The steam explosion severity is the main factor in the SSA process for removing hemicellulose, low severity (3.05) removed 36.7 $\% \sim 40.2 \%$ of hemicellulose, and high severity (3.64) removed $83.9 \% \sim 89.7 \%$. The chemical composition of DC samples indicates that the SSA process is effective for the removal of lignin and hemicellulose from corncob in a short $(5 \mathrm{~min})$ reaction time.

Table 1 - The lignin and carbohydrates content of L-SSA

\begin{tabular}{c|c|c|c|c|c|c|c}
\hline Sample & Glucose (\%) & Xylose (\%) & Arabinose (\%) & ASL (\%) & AIL (\%) & Ash (\%) & $\begin{array}{c}\text { Mass balance } \\
(\%)\end{array}$ \\
\hline L-SSA $_{3-3.05}$ & 1.45 & 7.04 & 2.49 & 2.13 & 83.65 & 0.33 & 97.09 \\
L-SSA $_{3-3.45}$ & 2.67 & 8.07 & 2.67 & 2.36 & 80.25 & 0.23 & 96.52 \\
L-SSA $_{3-3.64}$ & 2.46 & 10.45 & 2.70 & 2.01 & 78.07 & 0.27 & 95.96 \\
L-SSA $_{6-3.05}$ & 2.07 & 12.39 & 2.04 & 1.71 & 78.89 & 0.23 & 97.33 \\
L-SSA $_{6-3.45}$ & 3.13 & 12.40 & 4.42 & 1.46 & 77.14 & 0.30 & 98.85 \\
L-SSA $_{6-3.64}$ & 2.87 & 14.94 & 4.27 & 2.68 & 74.10 & 0.53 & 99.39 \\
L-SSA $_{9-3.05}$ & 3.01 & 13.12 & 4.48 & 1.68 & 71.58 & 0.33 & 94.20 \\
L-SSA $_{9-3.45}$ & 2.12 & 13.80 & 4.43 & 1.89 & 68.40 & 0.17 & 90.81 \\
L-SSA $_{9-3.64}$ & 3.67 & 14.08 & 4.70 & 2.15 & 70.64 & 0.17 & 95.41 \\
\hline
\end{tabular}

${ }^{1} \mathrm{ASL}$, acid soluble lignin; ${ }^{2} \mathrm{AIL}$, acid insoluble lignin. 
Table 2 - The lignin and carbohydrates content of delignified corncob (DC)

\begin{tabular}{|c|c|c|c|c|c|c|c|}
\hline Sample & Glucose (\%) & Xylose (\%) & Arabinose $(\%)$ & ASL (\%) & AIL (\%) & Ash (\%) & $\begin{array}{c}\text { Mass balance } \\
(\%)\end{array}$ \\
\hline $\mathrm{DC}_{3-3.05}$ & 65.67 & 28.49 & 2.49 & 1.88 & 3.32 & 0.23 & 102.67 \\
\hline $\mathrm{DC}_{3-3.45}$ & 71.11 & 23.48 & 2.67 & 3.01 & 3.30 & 0.38 & 104.05 \\
\hline $\mathrm{DC}_{3-3.64}$ & 82.45 & 6.24 & 2.70 & 3.12 & 3.23 & 0.29 & 97.43 \\
\hline $\mathrm{DC}_{6-3.05}$ & 66.11 & 28.14 & 2.04 & 2.45 & 2.77 & 0.26 & 101.77 \\
\hline $\mathrm{DC}_{6-3.45}$ & 70.54 & 23.76 & 4.42 & 1.67 & 3.53 & 0.24 & 104.16 \\
\hline $\mathrm{DC}_{6-3.64}$ & 83.34 & 6.34 & 4.27 & 2.47 & 2.70 & 0.28 & 99.4 \\
\hline $\mathrm{DC}_{9-3.05}$ & 67.00 & 27.86 & 4.48 & 3.00 & 3.80 & 0.19 & 106.33 \\
\hline $\mathrm{DC}_{9-3.45}$ & 66.38 & 27.49 & 4.43 & 4.13 & 3.37 & 0.34 & 106.14 \\
\hline $\mathrm{DC}_{9-3.64}$ & 78.56 & 5.21 & 5.70 & 4.47 & 3.32 & 0.35 & 97.61 \\
\hline
\end{tabular}

Table 3 - The assignments of L-SSA with different NaOH catalyzed concentration and steam explosion severity

\begin{tabular}{|c|c|c|c|c|c|c|c|c|c|}
\hline \multirow{2}{*}{ Assignments $/ \mathrm{cm}^{-1}$} & \multicolumn{3}{|c|}{$w_{\mathrm{NaOH}}=3 \%$} & \multicolumn{3}{|c|}{$w_{\mathrm{NaOH}}=6 \%$} & \multicolumn{3}{|c|}{$w_{\mathrm{NaOH}}=9 \%$} \\
\hline & 3.04 & 3.45 & 3.64 & 3.04 & 3.45 & 3.64 & 3.04 & 3.45 & 3.64 \\
\hline $\mathrm{C}-\mathrm{H}$ out of plane in positions 2,5 and $6(\mathrm{G}+\mathrm{S}$ unit $) / 833$ & 0.25 & 0.30 & 0.20 & 0.04 & 0.02 & 0.08 & 0.02 & 0.02 & 0.07 \\
\hline$\beta$-Linkage of cellulose/896 & 0.42 & 0.43 & 0.39 & 0.71 & 0.89 & 0.66 & 0.85 & 0.84 & 0.72 \\
\hline $\begin{array}{l}\text { Aromatic } \mathrm{C}-\mathrm{H} \text { in-plane deformation } \\
\text { for guaiacyl type } 1043\end{array}$ & 1.26 & 1.29 & 1.46 & 2.09 & 2.38 & 1.95 & 2.20 & 2.13 & 1.93 \\
\hline HSG unit/1166 & 0.92 & 0.96 & 0.96 & 1.55 & 1.75 & 1.49 & 1.73 & 1.61 & 1.40 \\
\hline Aromatic $\mathrm{C}-\mathrm{O}$ stretching/1247 & 0.96 & 0.94 & 0.95 & 1.22 & 1.34 & 1.16 & 1.33 & 1.27 & 1.17 \\
\hline Cellulose I and amorphous cellulose/1425 & 0.91 & 0.90 & 0.91 & 1.21 & 1.35 & 1.12 & 1.31 & 1.28 & 1.15 \\
\hline $\begin{array}{l}\mathrm{C}-\mathrm{H} \text { deformations (asymmetric } \\
\text { in }-\mathrm{CH}_{3} \text { and }-\mathrm{CH}_{2}-\text { )/1463 }\end{array}$ & 0.83 & 0.94 & 0.96 & 1.21 & 1.34 & 1.14 & 1.30 & 1.28 & 1.17 \\
\hline Aromatic skeletal vibrations $/ 1513$ & 1.00 & 1.00 & 1.00 & 1.00 & 1.00 & 1.00 & 1.00 & 1.00 & 1.00 \\
\hline $\begin{array}{l}\mathrm{C}=\mathrm{O} \text { stretching in conjugated } \\
p \text {-substituted aryl ketones } / 1635\end{array}$ & 0.93 & 0.95 & 1.00 & 1.26 & 1.35 & 1.14 & 1.30 & 1.35 & 1.18 \\
\hline $\begin{array}{l}\mathrm{C}=\mathrm{O} \text { stretching in unconjugated ketone, carbonyl, } \\
\text { and ester groups } / 1704\end{array}$ & 0.85 & 0.82 & 0.80 & 0.89 & 0.88 & 0.88 & 0.92 & 0.93 & 0.93 \\
\hline Aliphatic/2918 & 1.05 & 1.07 & 1.11 & 1.38 & 1.53 & 1.27 & 1.44 & 1.45 & 1.34 \\
\hline O-H stretching $/ 3400$ & 1.31 & 1.43 & 1.68 & 2.17 & 2.43 & 1.93 & 2.20 & 2.26 & 2.04 \\
\hline
\end{tabular}

Note: The intensity of aromatic skeleton vibration $\left(1513 \mathrm{~cm}^{-1}\right)$ was set as 1.00 and relative intensive of specific peaks were calculated.

Table 1 and Table 2 show that the different amounts of lignin and hemicellulose removed from corncob in one SSA treatment depends on operating conditions. The amount of sodium hydroxide used in the SSA process was greatly reduced in comparison with the boiling alkaline method $^{35}$, as the base-treated corncobs were drained before steam explosion, while the boiling alkaline depolymerization method retained this sodium hydroxide. In addition, the SSA operating time was reduced to 5 min. Consequently, the process of simultaneous steam explosion and alkaline depolymerization shows potential for application in the industrial utilization of lignocellulose.

\section{FTIR analysis of L-SSA}

The characteristics of L-SSA are dependent on the delignification process and original plant species. FTIR is a convenient method to analyze structure of L-SSA samples. The relative amounts of the chemical groups in all L-SSA samples were calculated by comparing the intensity with the bands of lignin aromatic skeletal vibration at $1513 \mathrm{~cm}^{-136}$ and are shown in Table 3. Based on FTIR analysis, the relative amount of hydroxyl groups $\left(3400 \mathrm{~cm}^{-1}\right)$ in the samples increased with the increase of severity factors, caused by structural changes in lignin and an increase in carbohydrate content. The signals of $\beta$-linkages of cellulose $\left(896 \mathrm{~cm}^{-1}\right)$ and signals of 
cellulose (cellulose I and amorphous cellulose, 1425 $\mathrm{cm}^{-1}$ ) were stronger, indicating that the carbohydrate content increased in L-SSA. These results agree with the chemical composition analysis. The increasing carbonyl groups $\left(1635 \mathrm{~cm}^{-1}, 1704 \mathrm{~cm}^{-1}\right)$ of L-SSA indicate that the lignin is oxidized during the steam explosion. There was no positive correlation between lignin content and the relative intensity of $p$-hydroxy phenyl-guaiacyl-syringyl (HSG) units. The low coefficient of correlation between these values can be attributed to the different amounts of carbohydrate present in the L-SSA, which disturbs this coefficient.

\section{Molecular weight average analysis of L-SSA}

The values of weight average molecular weight $\left(M_{w}\right)$ and number average molecular weight $\left(M_{n}\right)$ were determined using GPC. Polystyrene sulfonic acid salts of different molecular weights were employed for preparing GPC calibration curves. The $M_{w}$ and $M_{n}$ of all L-SSA samples are shown in Table 4. A relationship between molecular weight and experimental conditions was observed that indicated the $M_{w}$ and $M_{n}$ of L-SSA samples decreased with an increase in steam-explosive severity factor. This suggests that the depolymerization of lignin takes place with the SSA process. A high sodium hydroxide impregnating concentration can also prompt lignin depolymerization. However, the molecular weight of the resulting L-SSA was still quite high, because lignin oligomers with high molecular weight were formed. Lignin de/re-polymerization happens simultaneously in the presence of sodium hydroxide. In addition, the high temperature and high pressure of steam explosion can enhance the lignin de/re-polymerization.

\section{L-SSA of 2D HSQC NMR}

The 2D NMR spectra of L-SSA with different sodium hydroxide concentrations and steam explosion severities are shown in Fig. 1. The assignments Table 4-GPC results of L-SSA isolated from corncob

\begin{tabular}{c|c|c|c} 
Sample & $M_{w}$ & $M_{v}$ & $M_{w} / M_{v}$ \\
\hline L-SSA $_{3.305}$ & 26810 & 1320 & 20.31 \\
\hline L-SSA $_{3-3.45}$ & 21540 & 996 & 21.63 \\
L-SSA $_{3-3.64}$ & 17931 & 932 & 19.24 \\
L-SSA $_{6-3.05}$ & 17018 & 996 & 17.08 \\
L-SSA $_{6-3.45}$ & 14657 & 945 & 15.51 \\
L-SSA $_{6-3.64}$ & 5315 & 643 & 8.27 \\
L-SSA $_{9-3.05}$ & 11709 & 839 & 13.96 \\
L-SSA $_{9-3.45}$ & 9646 & 659 & 14.64 \\
L-SSA $_{9-3.64}$ & 7671 & 655 & 11.71 \\
& & & \\
\hline
\end{tabular}

of lignin and carbohydrate signals are provided in Table S2 and Table S3 ${ }^{37,38,39}$. In the side chain area of the L-SSA $\left(\delta_{\mathrm{C}} / \delta_{\mathrm{H}}=50-90 / 2.5-6.0\right)$, methoxyl groups are present in all samples at $\delta_{\mathrm{C}} / \delta_{\mathrm{H}} 55.8 / 3.72$. Obvious structural differences could be observed when treatment was performed with different steam explosion severities and different sodium hydroxide concentrations (Fig. 1 and Fig. S2). The linkages between lignin subunits were $\beta$-ether (mainly $\beta-O-4$ linkages, A and A' in Fig. 2) using a 3.05/3.45 severity factor and $3 \%$ sodium hydroxide concentration. Decrease in lignin inter-linkages and increase in carbohydrates signals can be observed in high severity factor and high sodium hydroxide concentration (Fig. 1 and Fig. S2). This interesting phenomenon of varied $\beta-O-4$ linkages was attributed to the depolymerization of $\beta-O-4$ bonds and the re-polymerization of lignin degradation products. Base-catalyzed depolymerization is often used to cleave the $\beta-O-4$ bonds and produce phenolic compounds, such as aldehydes, acids and alcohols ${ }^{40}$. However, the use of base catalysis on lignin depolymerization is not efficient due to a re-polymerization reaction. Unstable lignin intermediates can form the higher molecular weight products through a condensation reaction. Carbanions are likely formed during the depolymerization/re-polymerization on phenomenon that $\beta$-O- 4 content decreased and C-C condensed structures increased ${ }^{41}$.

In the aromatic area $\left(\delta_{\mathrm{C}} / \delta_{\mathrm{H}}=100-135 / 5.5-8.5\right)$, signals of guaiacyl units $(\mathrm{G})$, syringyl unit $(\mathrm{S})$, and $p$-hydroxyphenyl unit $(\mathrm{H})$ are observed in samples treated using 3.05/3.45 severity factor with $3 \%$ sodium hydroxide concentration, which indicates that the lignin from the corncob is typical GSH type lignin (Fig. 1). The intensity of $\mathrm{G}, \mathrm{S}$, and $\mathrm{H}$ subunits signals decreased with an increase in severity factor and sodium hydroxide concentration (Fig. 1 and Fig. S2). This was probably the result of decreasing the identical monomeric products in pyrolytic and recondensation reactions with increasing severity factors and sodium hydroxide concentrations ${ }^{39}$.

Carbohydrates signals of L-SSA could be observed both in the aliphatic region and the anomeric region of the spectra, which resulted primarily from the presence of hemicellulose depolymerization products, since there was no specific step to purify the lignin from the precipitate. With increasing steam explosion severity and increasing sodium hydroxide concentrations, more PhGlc linkages appeared in the HSQC spectrum, which indicated the enhancement of signal of cellulose binding to lignin (Fig.1 and Fig. S2). This result agrees with the result of the chemical composition analysis of L-SSA (Table 1). $\beta$-D-xylopyranoside showed clear $\mathrm{C}_{2}-\mathrm{H}_{2}, \mathrm{C}_{3}-\mathrm{H}_{3}, \mathrm{C}_{4}-\mathrm{H}_{4}, \mathrm{C}_{5}-\mathrm{H}_{5}$ signals at $\delta_{\mathrm{C}} / \delta_{\mathrm{H}} 72.5 / 3.04$, 

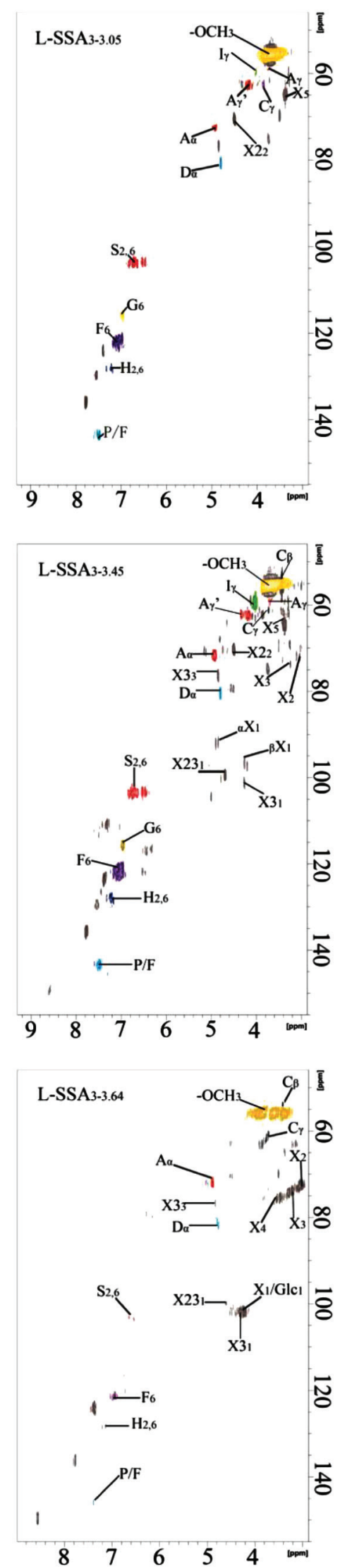

Fig. $1-2 D$ HSQC NMR spectrum of L-SSA samples isolated from corncob by different steam explosion severities and sodium hydroxide-catalyzed concentrations. $L-S S A_{3-3.05}, L-S S A_{3-3.45}$ and L-SSA ${ }_{3-3.64}$ represent the spectrum of the different operating conditions.<smiles>COc1cc(C)cc(OC(=O)C(O)C(=O)c2cc(OC)c(OC)c(OC)c2)c1</smiles>

$\mathbf{A}$

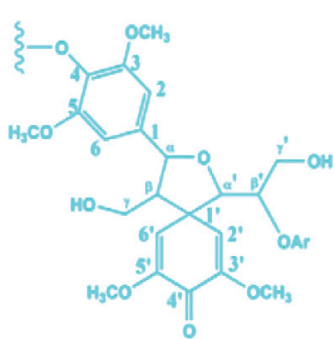

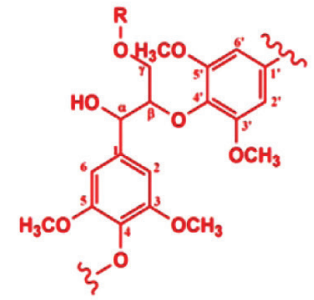

$\mathbf{A}^{*}$<smiles>CCOc1cc(C2Oc3c(OC)cc(C)cc3C(CO)C2c2cc(OC)c(OC)c(OC)c2)cc(OC)c1O</smiles>

C<smiles>COc1cc(/C=C/CO)cc(OC)c1OC</smiles>

I<smiles>[Z]Oc1ccc(C=CC(=O)OC)cc1OC</smiles>

F<smiles>COc1cc([N+](=O)[O-])cc(OC)c1OC</smiles><smiles>COc1ccc([N+](=O)[O-])cc1OC</smiles><smiles>CCOc1ccc([N+](=O)[O-])cc1</smiles><smiles>COc1cc(C)cc(OC)c1OC</smiles>

Fig. 2 - Main classical side-chain linkages and aromatic subunits of L-SSA from corncob detected by $2 D$ HSQC NMR spectrum: (A) $\beta-O-4$ 'aryl ether linkages with a free $-\mathrm{OH}$ at the $\gamma$-carbon; (A') $\beta$-O-4' aryl ether linkages with acetylated $-\mathrm{OH}$ at the $\gamma$-carbon; $(C)$ phenylcoumarane substructures formed by $\beta-5$ ' and $\alpha-O-4$ ' linkages; (D) spirodienone substructures formed by $\beta-1$ ' and $\alpha$-O- $\alpha$ ' linkages; (I) p-hydeoxycinnamyl alcohol end groups; (F) ferulates; (S) syringyl units; $(G)$ guaiacyl units; (H) p-hydroxyphenyl units; (PhGlc) phenyl glycoside.

$73.8 / 3.22,75.4 / 3.60$ and $62.6 / 3.41$ in the aliphatic region, respectively. Obvious signals of $2-O$-acetyl- $\beta$-D-xylopyranoside are observed at $\delta_{\mathrm{C}} / \delta_{\mathrm{H}}$ 73.2/4.46 $\left(\mathrm{X}_{2}\right)$ and $\delta_{\mathrm{C}} / \delta_{\mathrm{H}} 74.8 / 4.83\left(\mathrm{X}_{3}\right)$, which indicate that xylose is the main carbohydrate, and its $\mathrm{C}_{2}$ and $\mathrm{C}_{3}$ positions are acylated (Fig. 1, Fig. S1, and Table S3). In the anomeric region, $\mathrm{C}_{1}-\mathrm{H}_{1}$ correlations for the $\beta$-D-xlopyranoside $\left(\mathrm{X}_{1}\right)$ are overlapped with the $\mathrm{C}_{1}-\mathrm{H}_{1}$ correlations of $\beta$-D-glucopyranoside $\left(\mathrm{Glc}_{1}\right)$ at $\delta_{\mathrm{C}} / \delta_{\mathrm{H}} \quad 103.2 / 4.20$. The 3 - $O$-acetyl- $\beta$-D-xylopyranoside (X3 $\left.{ }_{1}\right)$ shows strong 
$\mathrm{C}_{1}-\mathrm{H}_{1}$ correlations at $\delta_{\mathrm{C}} / \delta_{\mathrm{H}} 101.6 / 4.32$ (Fig. 1, Fig. S1, and Table S3).

The SSA process efficiently removes most lignin and a portion of the carbohydrate, especially hemicellulose. The relative amount of carbohydrate in L-SSA samples shows a positive correlation with steam explosion severity and sodium hydroxide concentration. Strong steam explosion severity and high sodium hydroxide concentration lead to more lignin de/re-polymerization, which results in relatively increasing carbohydrate content.

\section{Cellulose structure of DC}

WAXS has been widely employed to determine the cellulose structural characteristics. The diffraction patterns of DC showed its structure following the SSA process. The diffraction peaks of cellulose I, at $2 \theta$ of $15.1^{\circ}, 16.8^{\circ}, 21.0^{\circ}, 22.8^{\circ}$ and $34.6^{\circ}$, correspond to the $1 \overline{1} 0,110,012,200$ and 004 crystallographic planes ${ }^{42}$. Cellulose II shows diffraction peaks at $12.2^{\circ}, 20.0^{\circ}, 22.2^{\circ}$, corresponding to the 1 $1 \overline{1} 0,110$ and 200 lattice planes ${ }^{43}$. WAXS spectra of DC samples are shown in Fig. 3.

The WAXS peaks of DC samples shifted to lower angles, suggesting that the cellulose was distorted with low order structures ${ }^{22}$. All DC samples showed clear peaks at $16.4^{\circ}$ and $22.5^{\circ}$, indicating that the cellulose of DC was cellulose I. However, the peaks of cellulose II could be observed when the sodium hydroxide concentration increased to 9 $\%$. The cellulose I chains stack in a parallel arrangement style in plant cell, and cellulose II lies in an antiparallel arrangement style ${ }^{44}$. The reason for this structural conformation at high sodium hydroxide concentrations is the swelling of cellulose fiber. Additionally, in all DC samples the crystal index (CrI) increased with the increase of steam explosive severity factors (Fig. 4). At a given sodium hydroxide concentration, higher CrI was observed with increased severity factor (Fig. 4). This is because more amorphous hemicellulose and lignin are extracted by the increasing steam explosive severity factor. The WAXS results indicated that the DC pattern after the SSA pretreatment belonged to cellulose I with the sodium hydroxide concentration of 3 $\%$ and $6 \%$. However, $\mathrm{DC}_{9-3.05}, \mathrm{DC}_{9-3.45}, \mathrm{DC}_{9-3.64}$ are composed of a mixture of cellulose I and cellulose II. Thus, the sodium hydroxide concentration and steam-explosive severity factor have combined effects on cellulose structures.

\section{Effects of cellulose structural changes on enzymatic hydrolysis}

Cellulose enzymatic hydrolysis is significantly influenced by its structure. Enzymatic hydrolysis experiments on all DC samples and UC sample were carried out to investigate the relationships between cellulose structure and enzymatic saccharification. $\mathrm{DC}_{3-3.05}$ had the highest cellulose conversion
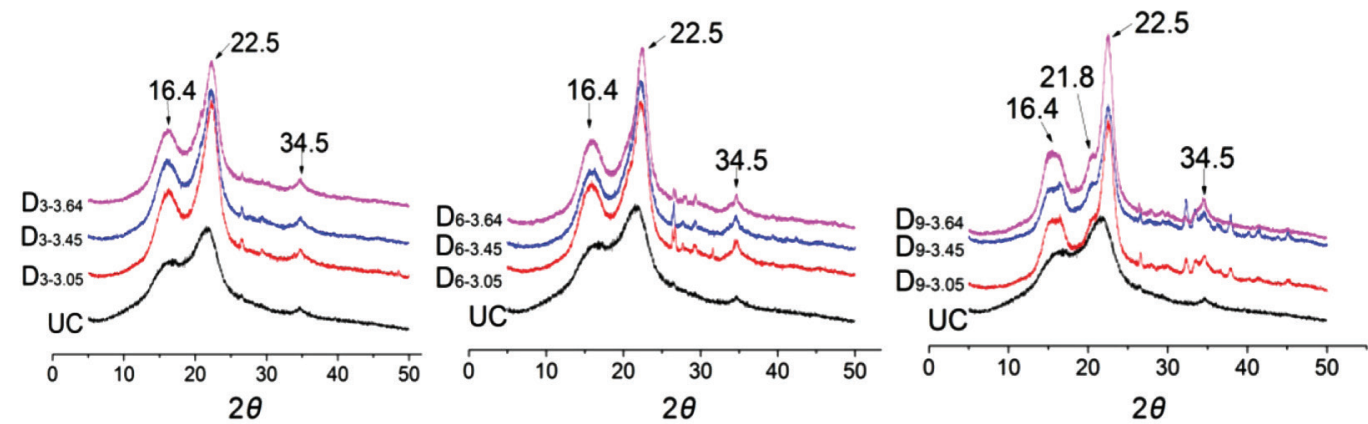

Fig. 3 -WAXS patterns of the delignified samples

$D C_{3-3.05}, D C_{6-3.05}, D C_{9-3.05}, D C_{3-3.45}, D C_{6-3.45}, D C_{9-3.45}, D C_{3-3.64}, D C_{6-3.64}, D C_{9-3.64}$
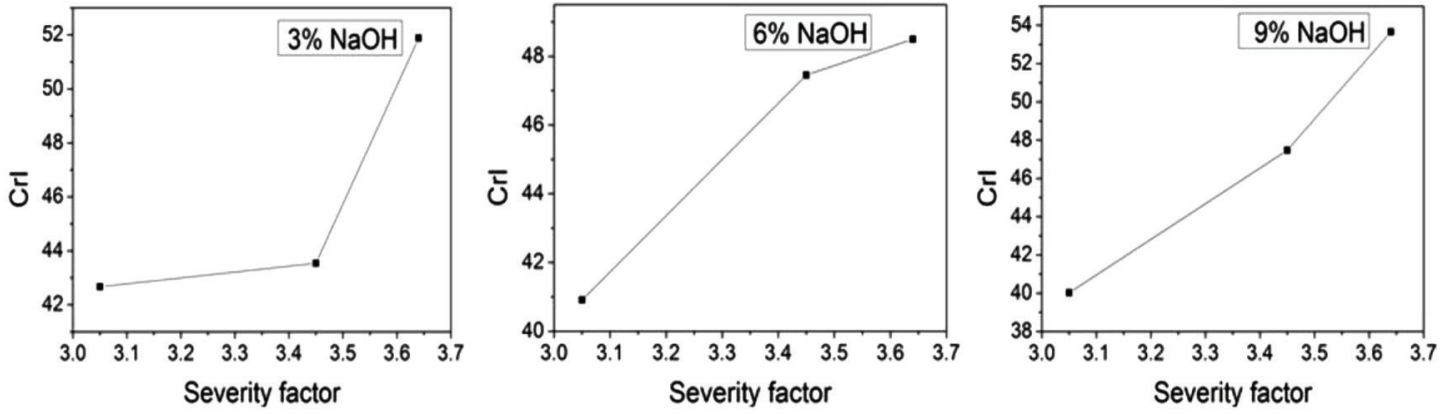

Fig. 4 -Relationship of cellulose CrI and steam explosion severity at various sodium hydroxide concentrations 

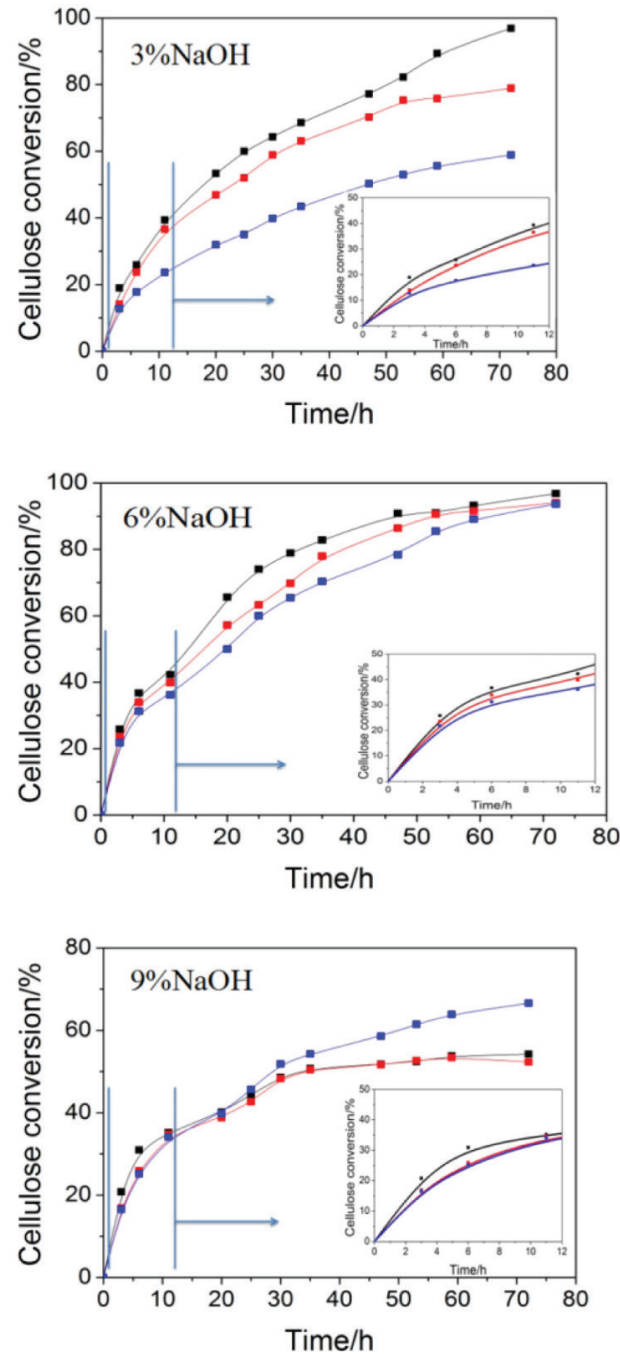

Fig. 5 - Enzymatic hydrolysis of DC samples at different steam explosion severities of 3.05 (black), 3.45 (red) and 3.64 (blue)

(96 \%), $\mathrm{DC}_{6-3.05}, \mathrm{DC}_{6-3.45}, \mathrm{DC}_{6-3.64}$ also had high cellulose conversion (>90\%) (Fig. 5 and Fig. S3). Meanwhile, the cellulose digestibility of $\mathrm{DC}_{9-3,64}$ only reached $66 \%$ after $72 \mathrm{~h}$. This illustrates that there is no specific correlation between cellulose conversion and cellulose structures. $\mathrm{DC}_{9-3.05}, \mathrm{DC}_{3-3.64}$, $\mathrm{DC}_{9-3.45}, \mathrm{DC}_{9-3.64}$ had low reducing sugar yield probably due to their high ratio of lignin (ASL+AIL):cellulose (glucose) (Table 2). Lignin has a negative charge at $\mathrm{pH} 4.8$, while cellulase, including $\beta$-glucosidase I, EG III, EG II, and CBH II, are positively charged at $\mathrm{pH} 4.8^{35}$. Positively charged cellulase can be adsorbed by negatively charged lignin, therefore inhibiting the action of cellulase on $\mathrm{DC}_{9-3.05}, \mathrm{DC}_{3-3.64}, \mathrm{DC}_{9-3.45}, \mathrm{DC}_{9-3.64}$ samples. This result also shows that saccharification is not only affected by cellulose structures, but also by other factors, such as lignin content, the accessibili- ty of cellulase to cellulose, and the degree of cellulose polymerization ${ }^{45}$. However, we observe a clear correlation between the rate of cellulose digestion and CrI (Fig. 4, Fig. 5) with a low CrI showing a high initial rate of enzymatic hydrolysis. A low CrI value indicates the presence of amorphous cellulose, which is easily accessed and hydrolyzed by cellulase.

\section{Conclusion}

The simultaneous steam explosion and sodium hydroxide pretreatment can result in the isolation of lignin or lignin and hemicellulose from corncob in reduced time and with lower sodium hydroxide consumption. This process significantly affects the structure of lignin and cellulose. High severity and high sodium hydroxide concentrations can lead to the breakdown of C-O linkages and re-polymerization of lignin substructures. Carbohydrates were bound with lignin by phenyl glycoside linkages. More carbohydrate was released from corncob, since the hemicellulose was dissolved under high severity and high sodium hydroxide concentrations. A well-delignified corncob shows a high cellulose content. Cellulose is also swelled by sodium hydroxide concentrations resulting in a change in cellulose crystal structure, and higher saccharification performance.

\section{ACKNOWLEDGEMENTS}

This work was supported by the National Key Research and Development Program of China (No. 2016YFD0400604), State Key Laboratory of Pulp and Paper Engineering (201760), Natural Science Foundation of China (NSFC 21576153), Beijing Natural Science Foundation (5162019), National High-tech Research and Development Program (2015AA021001) and Chinese 111 Project (B13005).
Abbreviation
SSA - Simultaneous steam-explosion and alkaline- depolymerization
L-SSA - Lignin from simultaneous steam-explosion and alkaline-depolymerization
WAXS - Wide angle X-ray scattering
DC - Delignified corncob
UC - Untreated corncob
AIL - Acid insoluble lignin
ASL - Acid soluble lignin 
186 X. Ouyang et al., Effect of Simultaneous Steam Explosion and Alkaline Depolymerization, Chem. Biochem. Eng. Q., 32 (2) 177-189 (2018)

\section{Supple me ntary Materials}

Table S 1 - Percentage of removed lignin and hemicelluloses in corncob after simultaneous steam explosion and alkaline depolymerization

\begin{tabular}{l|c|c}
\hline Sample & Lignin $(\%)^{\mathrm{a}}$ & ${\text { Hemicellulose }(\%)^{\mathrm{b}}}^{\mathrm{b}}$ \\
\hline $\mathrm{DC}_{3-3.05}$ & 86.90 & 58.16 \\
$\mathrm{DC}_{3-3.45}$ & 85.33 & 85.79 \\
$\mathrm{DC}_{3-3.64}$ & 87.25 & 40.24 \\
$\mathrm{DC}_{6-3.05}$ & 86.95 & 47.62 \\
$\mathrm{DC}_{6-3.45}$ & 87.79 & 89.72 \\
$\mathrm{DC}_{6-3.64}$ & 83.32 & 36.71 \\
$\mathrm{DC}_{9-3.05}$ & 83.21 & 37.04 \\
$\mathrm{DC}_{9-3.45}$ & 81.30 & 83.94 \\
$\mathrm{DC}_{9-3.64}$ & 81.82 & 8.94 \\
\hline
\end{tabular}

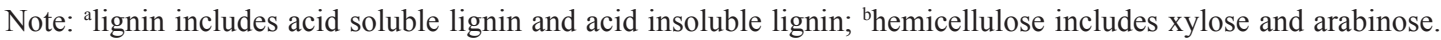

Table S 2 - Assignments of ${ }^{13} \mathrm{C}^{1} \mathrm{H}$ cross-signals in $2 \mathrm{D}$ HSQC NMR spectra of lignin fractions

\begin{tabular}{c|cl}
\hline Label & $\delta_{\mathrm{C}} / \delta_{\mathrm{H}}$ & \multicolumn{1}{c}{ Assignment } \\
\hline$-\mathrm{OCH}_{3}$ & $55.6 / 3.73$ & $\mathrm{C}-\mathrm{H}$ in methoxyls \\
$\mathrm{A} \gamma$ & $59.5 / 3.72$ & $\mathrm{C}-\mathrm{H}$ in $\beta$-O-4 substructures (A) \\
$\mathrm{A} \alpha$ & $71.8 / 4.88$ & $\mathrm{C}-\mathrm{H}$ in $\beta$-O-4 substructures (A) \\
$\mathrm{A} \gamma$ & $63.2 / 4.33$ & $\mathrm{C}-\mathrm{H}$ in $\gamma$-acylated $\beta$-O-4' substructures (A) \\
$\mathrm{C} \gamma$ & $62.5 / 3.73$ & $\mathrm{C}-\mathrm{H}$ in phenylcoumaran substructures (C) \\
$\mathrm{C}_{\beta}$ & $53.3 / 3.45$ & $\mathrm{C}-\mathrm{H}$ in phenylcoumaran substructures (C) \\
$\mathrm{I} \gamma$ & $61.4 / 4.10$ & $\mathrm{C}-\mathrm{H}$ in $p$-hydroxycinnamyl alcohol ending groups (I) \\
$\mathrm{D} \alpha$ & $8.19 / 4.90$ & $\mathrm{C}-\mathrm{H}$ in spirodienone substructures \\
$\mathrm{S}_{2,6}$ & $103.8 / 6.71$ & $\mathrm{C}-\mathrm{H}$ in etherified syringyl units (S) \\
$\mathrm{G}_{6}$ & $115.0 / 6.94$ & $\mathrm{C}-\mathrm{H}$ in guaiacyl units $(\mathrm{G})$ \\
$\mathrm{F}_{6}$ & $123 . / 7.11$ & $\mathrm{C}-\mathrm{H}$ in ferulate (F) \\
$\mathrm{H}_{2,6}$ & $128.3 / 7.22$ & $\mathrm{C}-\mathrm{H}$ in $p$-hydroxyphenyl units (H) \\
$\mathrm{P}_{2} \mathrm{~F}$ & $144.6 / 7.52$ & $\mathrm{C}-\mathrm{H}$ in $p$-coumarates (P) and ferulates (F) \\
\hline
\end{tabular}

Table S 3 - Assignments of the associated carbohydrate ${ }^{13} \mathrm{C}^{-1} \mathrm{H}$ cross-signals in $2 D \mathrm{H}$ NMRSQC spectra of lignin fractions

\begin{tabular}{ccl}
\hline Label & \multicolumn{1}{c}{$\delta_{\mathrm{C}} / \delta_{\mathrm{H}}$} & \multicolumn{1}{c}{ Assignment } \\
\hline $\mathrm{X}_{5}$ & $62.6 / 3.38$ & $\mathrm{C}_{5}-\mathrm{H}_{5}$ in $\beta$-D-xylopyranoside \\
$\mathrm{X}_{2}$ & $72.5 / 3.02$ & $\mathrm{C}_{2}-\mathrm{H}_{2}$ in $\beta$-D-xylopyranoside \\
$\mathrm{X}_{3}$ & $73.7 / 3.22$ & $\mathrm{C}_{3}-\mathrm{H}_{3}$ in $\beta$-D-xylopyranoside \\
$\mathrm{X}_{4}$ & $75.4 / 3.60$ & $\mathrm{C}_{4}-\mathrm{H}_{4}$ in $\beta$-D-xylopyranoside \\
$\mathrm{X}_{2}$ & $73.2 / 4.49$ & $\mathrm{C}_{2}-\mathrm{H}_{2}$ in 2 -O-acetyl- $\beta$-D-xylopyranoside \\
$\mathrm{X}_{3}$ & $74.8 / 4.83$ & $\mathrm{C}_{3}-\mathrm{H}_{3}$ in 3-O-acetyl- $\beta$-D-xylopyranoside \\
$\mathrm{X}_{3} 3_{1}$ & $98.9 / 4.71$ & $2,3-\mathrm{O}$-acetyl- $\beta$-D-xylopyranoside \\
$\mathrm{X}_{1}$ & $101.6 / 4.32$ & 3 -O-acetyl- $\beta$-D-xylopyranoside \\
Anomeric correlations $\left(\mathrm{C}_{1}-\mathrm{H}_{1}\right)$ & & \\
$\mathrm{X}_{1}(\mathrm{R})$ & $92.2 / 4.89$ & $(1 \rightarrow 4)-\alpha$-D-xylopyranoside \\
${ }_{\beta} \mathrm{X}_{1}$ & $94.9 / 4.26$ & $(1 \rightarrow 4)-\beta$-D-xylopyranoside \\
$\mathrm{X}_{1} / \mathrm{Glc}_{1}$ & $103.2 / 4.20$ & $\beta$-D-xylopyranoside/ $\beta$-D-glucopyranoside \\
$\mathrm{PhGlc}_{2}$ & $100.6 / 4.25$ & Phenyl glycoside linkages \\
\hline
\end{tabular}




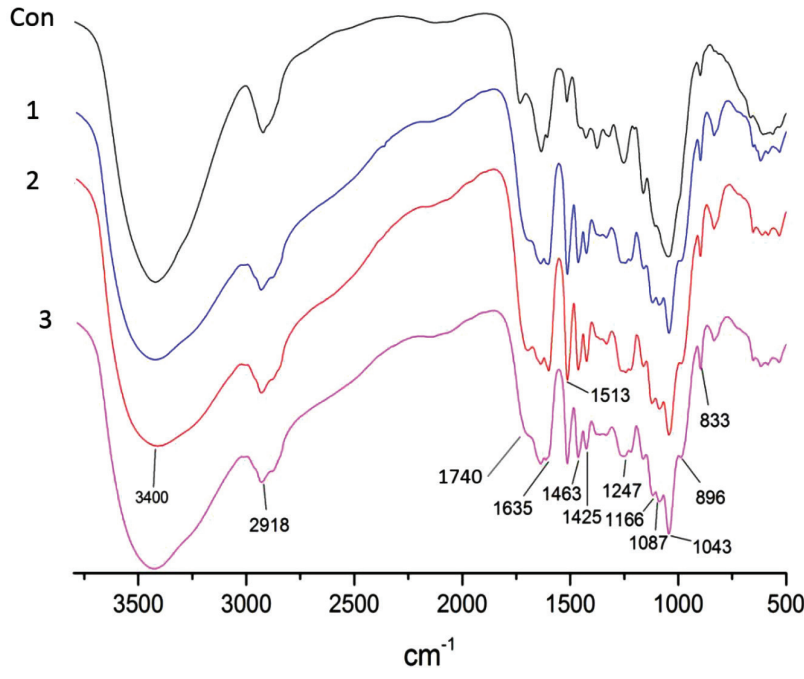

Fig. S 1 - FTIR spectrum of L-SSA samples isolated from corncob by different steam explosion severities and sodium hydroxide-catalyzed concentration. Con, untreated corncob; 1 , $L-S S A_{3-3.05} ; 2, L-S S A_{3-3.45} ; 3, L-S S A_{3-3.65}$.
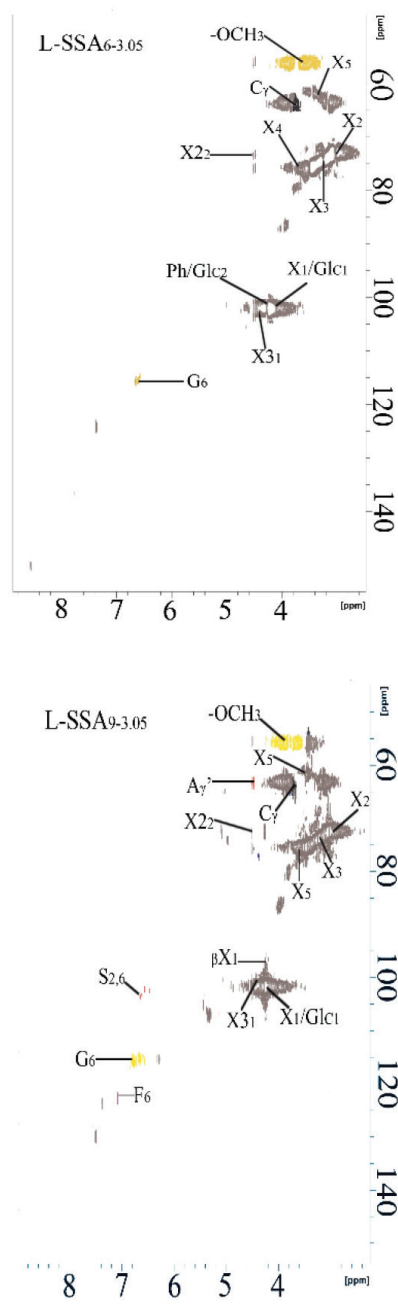

Fig. S $2-2 D$ HSOC NMR spectrum of L-SSA samples isolated from corncob by different steam explosion severities and sodium hydroxide-catalyzed concentrations. L-SSA ${ }_{6-3.05}$ and $L-S S A_{9-305}$ represent the spectrum of the different operating conditions.

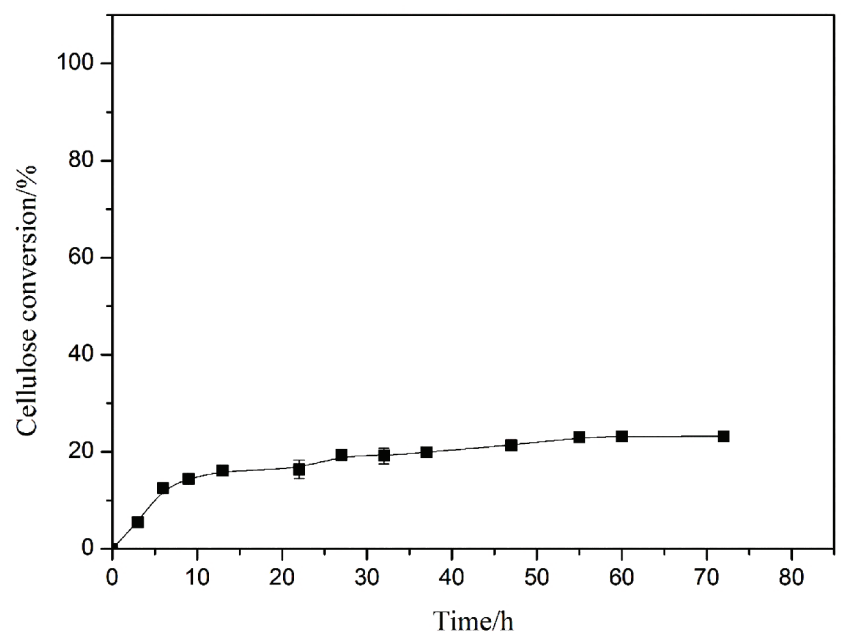

Fig. S3 - Enzymatic hydrolysis of cellulose from untreated corncob (UC)

\section{References}

1. Alvira, P., Tomás-Pejó, E., Ballesteros, M. J., Negro, M. J., Pretreatment technologies for an efficient bioethanol production process based on enzymatic hydrolysis: A review, Bioresour. Technol. 101 (2010) 4851. doi: https://doi.org/10.1016/j.biortech.2009.11.093

2. Kumar, P., Barrett, D. M., Delwiche, M. J., Stroeve, P., Methods for pretreatment of lignocellulosic biomass for efficient hydrolysis and biofuel production, Ind. Eng. Chem. Res. 48 (2009) 3713. doi: https://doi.org/10.1021/ie801542g

3. Balat, M., Balat, H., Öz, C., Progress in bioethanol processing, Prog. Energ. Combust. Sci. 34 (2008) 551.

4. Jørgensen, H., Kristensen, J. B., Felby, C., Enzymatic conversion of lignocellulose into fermentable sugars: Challenges and opportunities, Biofuels Bioprod. Bioref. 1 (2007) 119. doi: https://doi.org/10.1002/bbb.4

5. Mosier, N., Wyman, C., Dale, B., Elander, R., Lee, Y. Y., Holtzapple, M., Ladisch, M., Features of promising technologies for pretreatment of lignocellulosic biomass, Bioresour. Technol. 96 (2005) 673. doi: https://doi.org/10.1016/j.biortech.2004.06.025

6. Gao, Y., Xu, J., Zhang, Y., Yu, O., Yuan, Z., Liu, Y., Effects of different pretreatment methods on chemical composition of sugarcane bagasse and enzymatic hydrolysis, Bioresour. Technol. 144 (2013) 396.

doi: https://doi.org/10.1016/j.biortech.2013.06.036

7. Silverstein, R. A., Che, Y., Sharma-Shivappa, R. R., Boyette, M. D., Osborne, J., A comparison of chemical pretreatment methods for improving saccharification of cotton stalks, Bioresour. Technol. 98 (2007) 3000. doi: https://doi.org/10.1016/j.biortech.2006.10.022

8. Zhao, X., Zhang, L., Liu, D., Comparative study on chemical pretreatment methods for improving enzymatic digestibility of crofton weed stem, Bioresour. Technol. 99 (2008) 3729 . doi: https://doi.org/10.1016/j.biortech.2007.07.016

9. Taherzadeh, M. J., Karimi, K., Pretreatment of lignocellulosic wastes to improve ethanol and biogas production: A review, Int. J. Mol. Sci. 9 (2008) 1621. doi: https://doi.org/10.3390/ijms9091621 
10. Bali, G., Meng, X., Deneff, J. I., Sun, Q., Ragauskas, A. J., The effect of alkaline pretreatment methods on cellulose structure and accessibility, ChemSusChem 8 (2015) 275. doi: https://doi.org/10.1002/cssc.201402752

11. Joutsimo, O. P., Giacomozzi, D., Changes in cell wall structure during kraft processing of Pinus radiate, BioResources 10 (2015) 2461. doi: https://doi.org/10.15376/biores.10.2.2461-2478

12. Chundawat, S. P., Bellesia, G., Uppugundla, N., da Costa Sousa, L., Gao, D., Cheh, A. M., Agarwal, U. P., Bianchetti, C. M., Phillips Jr., G. N., Langan, P., Balan, V., Gnanakaran, S., Dale, B. E., Restructuring the crystalline cellulose hydrogen bond network enhances its depolymerization rate, JACS 133 (2011) 11163. doi: https://doi.org/10.1021/ja2011115

13. Wang, G., Chen., H., Fractionation of alkali-extracted lignin from steam-exploded stalk by gradient acid precipitation, Sep. Purif. Technol. 105 (2013) 98. doi: https://doi.org/10.1016/j.seppur.2012.12.009

14. Wang, G., Chen, H., Carbohydrate elimination of alkaline-extracted lignin liquor by steam explosion and its methylolation for substitution of phenolic adhesive, Ind. Crop. Prod. 53 (2014) 93. doi: https://doi.org/10.1016/j.indcrop.2013.12.020

15. Ballesteros, I., Negro, M. J., Oliva, J. M., Cabañas, A., Manzanares, P., Ballesteros, M., Methanol production from steam-explosion pretreated wheat straw, Appl. Biochem. Biotechnol. 130 (2006) 496. doi: https://doi.org/10.1385/ABAB:130:1:496

16. Vaithanomsat, P., Chuichulcherm, S., Apiwatanapiwat, W., Bioethanol production from enzymatically saccharified sunflower stalks using steam explosion as pretreatment, World Acad. Sci. Eng. Technol. 37 (2009) 140.

17. Chacha, N., Toven, K., Mtui, G., Katima, J., Mrema, G., Steam pretreatment of pine (Pinus patula) wood residue for the production of reducing sugars, Cellulose Chem. Technol. 45 (2011) 495.

18. Chen, W. H., Pen, B. L., Yu, C. T., Hwang, W. S., Pretreatment efficiency and structural characterization of rice straw by an integrated process of dilute-acid and steam explosion for bioethanol production, Bioresour. Technol. 102 (2011) 2916.

doi: https://doi.org/10.1016/j.biortech.2010.11.052

19. Ewanick, S., Bura, R., The effect of biomass moisture content on bioethanol yields from steam pretreated switchgrass and sugarcane bagasse, Bioresour. Technol. 102 (2011) 2651

doi: https://doi.org/10.1016/j.biortech.2010.10.117

20. Yu, Y., Feng, Y., Xu, C., Liu, J., Li, D., On site bio-detoxification of steam-exploded corn stover for cellulosic ethanol production, Bioresour. Technol. 102 (2011) 5123. doi: https://doi.org/10.1016/j.biortech.2011.01.067

21. Martin-Sampedro, R., Martin, J. A., Eugenio, M. E., Revilla, E., Villar, J. C., Steam explosion treatment of Eucalyptus globulus wood: Influence of operational conditions on chemical and structural modifications, BioResources 6 (2011) 4922.

22. Zhang, H., Fan, X., Qiu, X., Zhang, Q., Wang, W., Li, S., Deng, L., Koffas, M., Wei, D., Yuan, Q., A novel cleaning process for industrial production of xylose in pilot scale from corncob by using screw-steam-explosive extruder, $\mathrm{Bi}$ oproc. Biosyst. Eng. 37 (2014) 2425. doi: https://doi.org/10.1007/s00449-014-1219-0

23. Pan, Y. Q., Zhang, H. J., Qiu, X. L., Ouyang, X. H., Wang, W. Y., Li, S. X., Zhang, Q. X., Yuan, Q. P., Simulation and pilot test of xylose production using oxalic acid-saturated continuous steam explosion of corncob (In Chinese with English abstract), Chin. J. Process Eng. 14 (2013) 643.

24. Yuan, Q. P., Sun, L., Wang, X. Y., Wang, W. Y., Li, S. X., Wang, C. F., The green process and instrument for xylitol production from corncob, Science and Technology Awardsof Shandong Province, China, 2016, JB2015-3-15-R04.

25. Ouyang, X. H., Wang, W., Yuan, Q., Li, S., Zhang, Q., Zhao, $P$., Improvement of lignin yield and purity from corncob in the presence of steam explosion and liquid hot pressured alcohol, RSC Adv. 5 (2015) 61650. doi: https://doi.org/10.1039/C5RA12452B

26. Wang, S. J., Ouyang, X. H., Wang, W. Y., Yuan, Q. P., Yan, A. $X$., Comparison of ultrasound-assisted Fenton reaction and dilute acid-catalysed steam explosion pretreatment of corncobs: Cellulose characteristics and enzymatic saccharification, RSC Adv. 6 (2016) 76848. doi: https://doi.org/10.1039/C6RA13125E

27. Fan, X., Cheng, G., Zhang, H., Li, M., Wang, S., Yuan, Q., Effects of acid impregnated steam explosion process on xylose recovery and enzymatic conversion of cellulose in corncob, Carbohyd. Polym. 114 (2014) 21. doi: https://doi.org/10.1016/j.carbpol.2014.07.051

28. Overend, R. P., Chornet, E., Fractionation of lignocellulosis by steam-aqueous pretreatments, Philos. Trans. R. Soc. Lond. A 321 (1987) 523. doi: https://doi.org/10.1098/rsta.1987.0029

29. Sluiter, A., Hames, B., Ruiz, R., Scarlata, C., Sluiter, J., Templeton, D., Crocker, D., Determination of structural carbohydrates and lignin in biomass, Laboratory analytical procedure 1617 (2008) 1.

30. Focher, B., Palma, M., Canetti, M., Torri, G., Cosentino, $C$., Gastaldi, G., Structural differences between non-wood plant celluloses: Evidence from solid state NMR, vibrational spectroscopy and X-ray diffractometry, Ind. Crop. Prod. 13 (2001) 193. doi: https://doi.org/10.1016/S0926-6690(00)00077-7

31. Charlier, L., Mazeau, K., Molecular modeling of the structural and dynamical properties of secondary plant cell walls: Influence of lignin chemistry, J. Phys. Chem. B 116 (2012) 4163. doi: https://doi.org/10.1021/jp300395k

32. Sun, S. L., Wen, J. L., Ma, M. G., Sun, R. C., Enhanced enzymatic digestibility of bamboo by a combined system of multiple steam explosion and alkaline treatments, Appl. Energ. 136 (2014) 519. doi: https://doi.org/10.1016/j.apenergy.2014.09.068

33. Chakar, F. S., Ragauskas, A. J., Review of current and future softwood kraft lignin process chemistry, Ind. Crop. Prod. 20 (2004) 131 doi: https://doi.org/10.1016/j.indcrop.2004.04.016

34. Monteil-Rivera, F., Phuong, M., Ye, M., Halasz, A., Hawari, $J$., Isolation and characterization of herbaceous lignins for applications in biomaterials, Ind. Crop. Prod. 41 (2013) 356. doi: https://doi.org/10.1016/j.indcrop.2012.04.049

35. Kim, J. S., Lee, Y. Y., Kim, T. H., A review on alkaline pretreatment technology for bioconversion of lignocellulosic biomass, Bioresour. Technol. 199 (2016) 42. doi: https://doi.org/10.1016/j.biortech.2015.08.085

36. Nakagame, S., Chandra, R. P., Kadla, J. F., Saddler, J. N., The isolation, characterization and effect of lignin isolated from steam pretreated Douglas-fir on the enzymatic hydrolysis of cellulose, Bioresour. Technol. 102 (2011) 4507. doi: https://doi.org/10.1016/j.biortech.2010.12.082 
37. Yuan, T. Q., Sun, S. N., Xu, F., Sun, R. C., Characterization of lignin structures and lignin-carbohydrate complex (LCC) linkages by quantitative ${ }^{13} \mathrm{C}$ and $2 \mathrm{D}$ HSQC NMR spectroscopy, J. Agric. Food Chem. 59 (2001) 10604. doi: https://doi.org/10.1021/jf2031549

38. Bai, Y. Y., Xiao, L. P., Shi, Z. J., Sun, R. C., Structural variation of bamboo lignin before and after ethanol organosolv pretreatment, Int. J. Mol. Sci. 14 (2013) 21394. doi: https://doi.org/10.3390/ijms141121394

39. Rencoret, J., Marques, G., Gutiérrez, A., Nieto, L., Jiménez-Barbero, J., Martínez, Á. T., del Río, J. C., Isolation and structural characterization of the milled-wood lignin from Paulownia fortunei wood, Ind. Crop. Prod. 30 (2009) 137. doi: https://doi.org/10.1016/j.indcrop.2009.03.004

40. Toledano, A., Serrano, L., Labidi, J., Improving base catalyzed lignin depolymerization by avoiding lignin repolymerization, Fuel 116 (2014) 617.

doi: https://doi.org/10.1016/j.fuel.2013.08.071

41. Li, J., Henriksson, G., Gellerstedt, G., Lignin depolymerization/repolymerization and its critical role for delignification of aspen wood by steam explosion, Bioresour. Technol. 98 (2007) 3061.

doi: https://doi.org/10.1016/j.biortech.2006.10.018
42. Sebe, G., Ham-Pichavant, F., Ibarboure, E., Koffi, A. L., Tingaut, $P$., Supramolecular structure characterization of cellulose II nanowhiskers produced by acid hydrolysis of cellulose I substrates, Biomacromolecules 13 (2012) 570. doi: https://doi.org/10.1021/bm201777j

43. Oka, D., Kobayashi, K., Isobe, N., Ogawa, Y., Yokoyama, T., Kimura, S., Kim, U. J., Tokuyasu, K., Wada, M., Enzymatic hydrolysis of wood with alkaline treatment, J. Wood Sci. 59 (2013) 484. doi: https://doi.org/10.1007/s10086-013-1359-x

44. Cheng, G., Varanasi, P., Arora, R., Stavila, V., Simmons, B. A., Kent, M. S., Singh, S., Impact of ionic liquid pretreatment conditions on cellulose crystalline structure using 1-ethyl3-methylimidazolium acetate, J. Phys. Chem. B 116 (2012) 10049.

doi: https://doi.org/10.1021/jp304538v

45. Bian, J., Peng, F., Peng, X. P., Xiao, X., Peng, P., Xu, F., Sun, $R$. C., Effect of [Emim]Ac pretreatment on the structure and enzymatic hydrolysis of sugarcane bagasse cellulose, Carbohydr. Polym. 100 (2014) 211.

doi: https://doi.org/10.1016/j.carbpol.2013.02.059 